11 | 2007

Varia

\title{
Images et passages à l'époque médiévale
}

Centre d'études médiévales d'Auxerre, table ronde des 19-20 juin 2008

Dominique Donadieu-Rigaut

\section{(2) OpenEdition}

Journals

Édition électronique

URL : https://journals.openedition.org/cem/1093

DOI : 10.4000/cem.1093

ISSN : 1954-3093

Éditeur

Centre d'études médiévales Saint-Germain d'Auxerre

Édition imprimée

Date de publication : 15 août 2007

ISSN : 1623-5770

Référence électronique

Dominique Donadieu-Rigaut, "Images et passages à l'époque médiévale », Bulletin du centre d'études médiévales d'Auxerre | BUCEMA [En ligne], 11 | 2007, mis en ligne le 30 août 2007, consulté le 22

septembre 2022. URL : http://journals.openedition.org/cem/1093 ; DOI : https://doi.org/10.4000/cem. 1093

Ce document a été généré automatiquement le 22 septembre 2022.

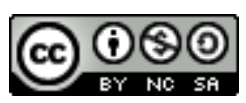

Creative Commons - Attribution - Pas d'Utilisation Commerciale - Partage dans les Mêmes Conditions 4.0 International - CC BY-NC-SA 4.0

https://creativecommons.org/licenses/by-nc-sa/4.0/ 


\section{Images et passages à l'époque médiévale}

Centre d'études médiévales d'Auxerre, table ronde des 19-20 juin 2008

\section{Dominique Donadieu-Rigaut}

1 Depuis les travaux fondateurs de Louis Marin (De la représentation, Paris, Gallimard/Le Seuil, 1994) et de Victor Stoïchita (L'instauration du tableau, Genève, Droz, 1999), nous savons combien le cadre a joué un rôle capital dans la formation du tableau moderne et la définition de l'espace de la représentation. Clôture de l'image, il autonomise l'œuvre par rapport au monde visible qui l'entoure, tout en imposant une manière ostentatoire d'appréhender le Représenté se donnant à voir comme tel.

2 Pour l'époque médiévale, la question se pose autrement. Même si les «cadres» n'étaient pas méconnus bien au contraire (que l'on pense par exemple aux véritables édicules de bois enchâssant les retables gothiques), ils assumaient des fonctions différentes dans la mesure où les panneaux, spécifiquement créés pour un lieu particulier (autel, chapelle, cellule...), entretenaient avec leur environnement immédiat des rapports nécessaires. En ce sens, les cadres avaient davantage pour rôle d'articuler l'œuvre à l'édifice ecclésial ou conventuel que de construire un espace pictural signifiant en le distinguant de tout ce qui relevait du « hors-cadre ».

3 Mais la problématique du cadre médiéval ne se borne pas, précisément, aux bords du panneau de bois, ni même aux seuls retables. Les images du Moyen Âge, peintes sur les murs ou dans les livres, sont elles aussi délimitées par des bordures trop souvent ignorées dans l'analyse des œuvres, les auteurs (et les photographes) se focalisant sur le « dedans » censé contenir à lui seul tout le signifiant. Pourtant, ces limites participent pleinement de l'image. Non seulement parce que ce sont elles qui délimitent, dans certains manuscrits, le «centre» de la page par opposition aux marginalia, mais aussi dans la mesure où elles concourent à établir des séquences et des rythmes visuels ordonnant le narratif dans un cycle donné.

4 Il s'agira dès lors de s'interroger sur les multiples fonctions de ces frises liminales, ainsi que sur leurs mises en œuvre, en accordant une attention particulière au caractère poreux, dynamique, voire énigmatique des frontières. Car si les bordures médiévales 
semblent au premier abord jouer exclusivement le rôle de barrières qui séparent, qui opposent de façon univoque, elles sont aussi et surtout des appels à la transgression, aux débordements. En un mot, des invitations à penser la transition et le transitoire sur un mode plus complexe.

Cette réflexion sera conduite selon deux axes thématiques :

1) Dépasser les limites : passages et transgressions de la bordure dans les images médiévales.

7 Cette première section de travaux sera consacrée à l'analyse aussi fine que possible des représentations médiévales (tous supports confondus) mettant en œuvre des phénomènes volontaires de franchissement des limites, de dépassement et de débordement du cadre. Nous nous interrogerons aussi sur la validité de la notion de «frise » qui a joué un si grand rôle en Histoire de l'art, tant pour désigner les «bords » du bâtiment que les « bords » de l'image.

2) Le rôle performatif des images-objets dans les rites de passage au Moyen Âge

En nous appuyant sur la notion "d'images-objets » définie par Jérôme Baschet (cf "L'image-objet ", in L'image, fonctions et usages des images dans l'Occident médiéval, Paris, Cahiers du Léopard d'Or, 5, 1996, p. 7-26), nous essaierons de comprendre comment les images peuvent prendre part aux rites de passage (baptême, mort, prise d'habit, entrée solennelle...) et plus globalement aux manifestations des états transitoires, et concourir ainsi à l'accomplissement d'un devenir autre.

\section{Participants pressentis :}

- Jérôme Baschet (EHESS, Paris)

- Dominique Donadieu-Rigaut (Université de Marne-la-Vallée - ARTeHIS)

- Katia Gimenez (Université de Bourgogne)

- Eliana Magnani (CEM Auxerre - ARTeHIS)

- Robert Marcoux (Université de Laval, Québec)

- Didier Méhu (Université de Laval, Québec)

- Dominic Olariu (Université de Düsseldorf)

- Anne-Orange Poilpré (Université de Nancy 2)

- Daniel Russo (Université de Bourgogne - ARTeHIS)

- Emanuela Toma (EHESS, Paris)

- Mélanie Terrisse (Université de Bourgogne - ARTeHIS) 